\title{
Alternate day fasting for weight loss in normal weight and overweight subjects: a randomized controlled trial
}

Krista A Varady*, Surabhi Bhutani, Monica C Klempel, Cynthia M Kroeger, John F Trepanowski, Jacob M Haus, Kristin K Hoddy and Yolian Calvo

\begin{abstract}
Background: Alternate day fasting (ADF; ad libitum "feed day", alternated with 25\% energy intake "fast day"), is effective for weight loss and cardio-protection in obese individuals. Whether these effects occur in normal weight and overweight individuals remains unknown. This study examined the effect of ADF on body weight and coronary heart disease risk in non-obese subjects.

Methods: Thirty-two subjects (BMI $20-29.9 \mathrm{~kg} / \mathrm{m}^{2}$ ) were randomized to either an ADF group or a control group for 12 weeks.

Results: Body weight decreased $(P<0.001)$ by $5.2 \pm 0.9 \mathrm{~kg}(6.5 \pm 1.0 \%)$ in the ADF group, relative to the control group, by week 12. Fat mass was reduced $(P<0.001)$ by $3.6 \pm 0.7 \mathrm{~kg}$, and fat free mass did not change, versus controls. Triacylglycerol concentrations decreased $(20 \pm 8 \%, P<0.05)$ and LDL particle size increased $(4 \pm 1 \AA, P<0.01)$ in the ADF group relative to controls. CRP decreased $(13 \pm 17 \%, P<0.05)$ in the ADF group relative to controls at week 12. Plasma adiponectin increased $(6 \pm 10 \%, P<0.01)$ while leptin decreased $(40 \pm 7 \%, P<0.05)$ in the ADF group versus controls by the end of the study. LDL cholesterol, HDL cholesterol, homocysteine and resistin concentrations remained unchanged after 12 weeks of treatment.

Conclusion: These findings suggest that ADF is effective for weight loss and cardio-protection in normal weight and overweight adults, though further research implementing larger sample sizes is required before solid conclusion can be reached.
\end{abstract}

Keywords: Alternate day fasting, Calorie restriction, Weight loss, Cholesterol, Blood pressure, Adipokines, Coronary heart disease, Non-obese humans

\section{Introduction}

Intermittent fasting regimens, particularly alternate day fasting (ADF) protocols, have gained considerable popularity in the past decade. Alternate day fasting involves a "fast day" where individuals consume $25 \%$ of energy needs, alternated with a "feed day" where subjects eat ad libitum [1]. Only a handful of studies have been performed to test the effects of ADF on body weight and coronary heart disease (CHD) risk reduction, and almost all of these studies have been undertaken in obese populations (BMI $30-39.9 \mathrm{~kg} / \mathrm{m}^{2}$ ) [2-4]. Results from these initial trials indicate that

* Correspondence: varady@uic.edu

Department of Kinesiology and Nutrition, University of Illinois at Chicago, 1919 West Taylor Street, Room 506 F, Chicago, IL 60612, USA
ADF is effective for weight loss (5-6\% reductions in body weight) and visceral fat mass loss $(5-7 \mathrm{~cm}$ reductions in waist circumference) in 8-12 weeks of treatment [2-4]. These reports also suggest that ADF may aid in the retention of lean mass in obese individuals [2-4]. In addition to these favorable body composition changes, improvements in CHD risk have also been noted. For instance, decreases in LDL cholesterol concentrations (20-25\%), triacylglycerol concentrations (15-30\%), and increases in LDL particle size are often observed with short-term ADF (8-12 weeks) [2-4]. Beneficial changes in blood pressure and adipokine profile (i.e. increases in adiponectin, and decreases in leptin and resistin) have also been reported [2-4]. Taken together, this preliminary

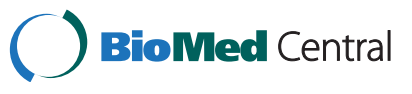


work suggests that ADF may be effective for weight loss and CHD risk reduction in obese adults.

An important question that remains unresolved is whether the favorable effects of ADF can also be observed in normal weight and overweight populations. Only two human studies [5,6] have tested the effect of ADF on body weight and CHD risk in non-obese subjects. In a study by Heilbronn et al. [5], normal weight men and women (BMI $23 \mathrm{~kg} / \mathrm{m}^{2}$ ) participated in an ADF regimen for 3 weeks. Body weight decreased by $2 \%$ from baseline, while triacylglycerol concentrations decreased only in men [5]. Contrary to these findings, Halberg et al. [6] demonstrated no change in body weight after 2 weeks of ADF in overweight men (BMI $26 \mathrm{~kg} / \mathrm{m}^{2}$ ). While these trials $[5,6]$ lay some groundwork, they are limited by their short durations (2-3 weeks) and their lack of a control group. As such, a longer-term trial (12 weeks) that employs a control group is well warranted.

Accordingly, the present study examined the effect of ADF on body weight, body composition, and CHD risk parameters in both normal weight and overweight adults in a 12-week randomized controlled feeding trial. We hypothesized that ADF would reduce body weight and CHD risk in normal weight and overweight participants, when compared to controls.

\section{Subjects and methods \\ Subjects}

Subjects were recruited from the Chicago area by means of advertisements placed around the University of Illinois, Chicago campus. A total of 107 individuals expressed interest in the study, but only 32 were recruited to participate after screening via a preliminary questionnaire and BMI assessment (Figure 1). Inclusion criteria were as follows: BMI between 20 and $29.9 \mathrm{~kg} / \mathrm{m}^{2}$; age between 35 and 65 years; pre-menopausal or post-menopausal (absence of menses for more than 2 years); lightly active $(<3 \mathrm{~h}$ /week of light intensity exercise at 2.5 to 4.0 metabolic equivalents (METs) for 3 months prior to the study); weight stable for 3 months prior to the beginning of the study ( $<4 \mathrm{~kg}$ weight loss or weight gain); nondiabetic; no history of cardiovascular disease; non-smoker; and not taking weight loss, lipid- or glucose-lowering medications. The experimental protocol was approved by the University of Illinois, Chicago, Office for the Protection of Research Subjects, and all research participants gave their written informed consent to participate in the trial. The research protocol was in compliance with the Helsinki Declaration.

\section{Study design}

\section{Experimental design}

A 12-week, randomized, controlled, parallel-arm feeding trial was implemented as a means of testing the study

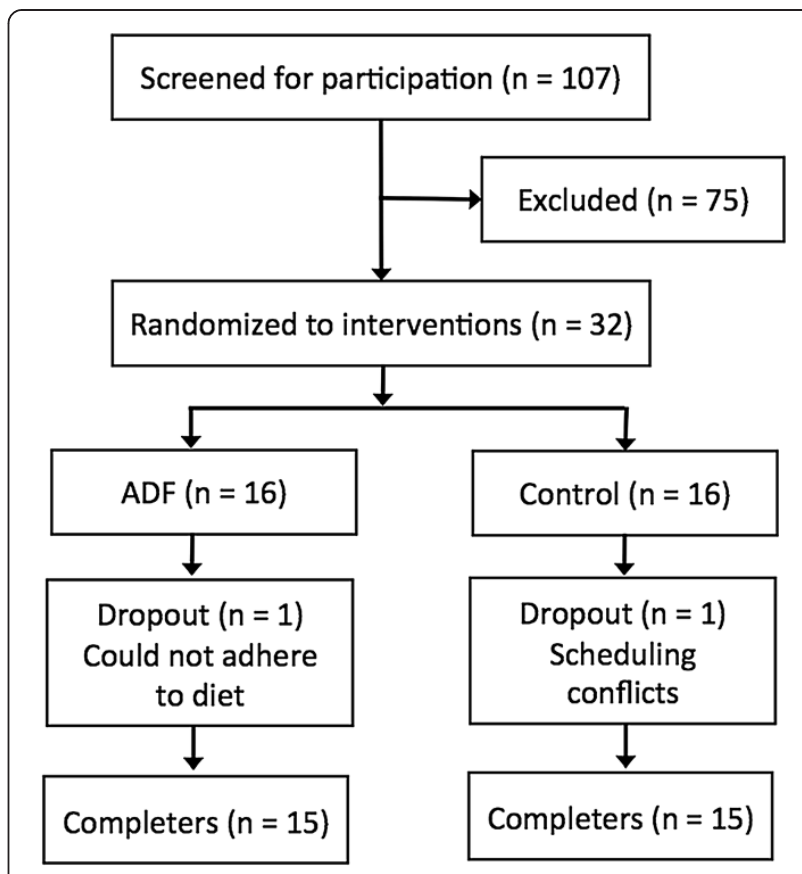

Figure 1 Study flow chart. ADF: Alternate day fasting.

objectives. Subjects were randomized by KAV by way of a stratified random sample. Subjects were first divided into strata based on sex (M/F), age (35-50 y/51-65 y), and BMI $\left(20-24.9 \mathrm{~kg} / \mathrm{m}^{2} / 25-29.9 \mathrm{~kg} / \mathrm{m}^{2}\right)$, and then subjects from each stratum were randomized 1:1 into either the ADF or control group (Figure 1).

\section{Diet protocol}

During the dietary intervention period, ADF subjects consumed $25 \%$ of their baseline energy needs on the fast day $(24 \mathrm{~h})$, and then ate ad libitum on each alternating feed day $(24 \mathrm{~h})$. Energy needs for each subject were determined by the Mifflin equation [7]. The feed and fast days began at midnight each day, and all fast day meals were consumed between $12.00 \mathrm{pm}$ and $2.00 \mathrm{pm}$ to ensure that each subject was undergoing the same duration of fasting. ADF subjects were provided with meals on each fast day (ranging from 400-600 kcal), and ate ad libitum at home on the feed day. All ADF fast day meals were prepared in the metabolic kitchen of the Human Nutrition Research Center (HNRU) at the University of Illinois, Chicago. Fast day meals were provided as a 3-day rotating menu, and were formulated based on the American Heart Association (AHA) guidelines $(30 \% \mathrm{kcal}$ from fat, $15 \% \mathrm{kcal}$ from protein, $55 \% \mathrm{kcal}$ from carbohydrate) [8]. All meals were consumed outside of the research center. ADF subjects were permitted to consume energy-free beverages, tea, coffee, and sugarfree gum, and were encouraged to drink plenty of water. Control subjects were permitted to eat ad libitum 
every day, and were not provided with meals from the research center.

\section{Blood collection protocol}

Twelve-hour fasting blood samples were collected between $6.00 \mathrm{am}$ and $9.00 \mathrm{am}$ at baseline (week 1) and post-treatment (week 12). Participants were instructed to avoid exercise, alcohol, and coffee for $24 \mathrm{~h}$ before each visit. Blood was centrifuged for $15 \mathrm{~min}$ at $520 \times \mathrm{g}$ and $4^{\circ} \mathrm{C}$ to separate plasma from $\mathrm{RBCs}$, and was stored at $-80^{\circ} \mathrm{C}$ until analysed.

\section{Analyses}

\section{Energy intake on feed and fast days}

During the 12-week diet intervention, subjects in the ADF group were instructed to eat only the foods provided on each fast day. To assess energy intake on the fast days, ADF subjects were asked to report any extra food items consumed (i.e. those not provided) using an "Extra food log". Additionally, subjects were instructed to return any leftover food items to the HNRU for weighing. To assess energy intake on the feed days, ADF and control subjects were asked to complete a 3 -day food record on 2 feed days during the week, and on 1 feed day during the weekend, at week 1 and 12 . At baseline, the Research Dietician provided $15 \mathrm{~min}$ of instruction to all participants on how to complete the food records. These instructions included verbal information and detailed reference guides on how to estimate portion sizes and record food items in sufficient detail to obtain an accurate estimate of dietary intake. All dietary information from the food logs/records was entered into the food analysis program, Nutritionist Pro (version 5, Axxya Systems, Stafford, TX) to assess energy intake.

\section{Hunger, satisfaction, and fullness}

A validated visual analog scale (VAS) was used to measure hunger, fullness, and satisfaction with the ADF diet [9]. The scale was completed on 3 fast days (before bedtime) at week 1 and 12. In brief, the VAS consisted of $100-\mathrm{mm}$ lines, and subjects were asked to make a vertical mark across the line corresponding to their feelings from 0 (not at all) to 100 (extremely) for hunger, satisfaction, or fullness. Quantification was performed by measuring the distance from the left end of the line to the vertical mark.

\section{Weight loss and body composition}

Body weight was assessed to the nearest $0.25 \mathrm{~kg}$ at the beginning of every week without shoes and in light clothing using a balance beam scale at the HNRU (HealthOMeter, Sunbeam Products, Boca Raton, FL). BMI was assessed as $\mathrm{kg} / \mathrm{m}^{2}$. Body composition (fat mass and fat free mass) was measured using dual $x$-ray absorptiometry (DXA) (Hologic QDR 4500 W, Hologic Inc., Waltham, MA).

\section{Lipid coronary heart disease risk factors}

Plasma total cholesterol, HDL-cholesterol, and triacylglycerol concentrations were measured in duplicate using enzymatic kits (Biovision Inc., Moutainview, CA) at week 1 and 12. The concentration of LDL-cholesterol was calculated using the Friedewald, Levy and Fredrickson equation. LDL particle size was measured by linear polyacrylamide gel electrophoresis (Quantimetrix Lipoprint System, Redondo Beach, CA, USA) at week 1 and 12 [10,11]. High-resolution $3 \%$ polyacrylamide gel tubes were used for electrophoresis. Briefly, $25 \mu \mathrm{L}$ of sample was mixed with $200 \mu \mathrm{L}$ of liquid loading gel containing Sudan black, and added to the gel tubes. After photopolymerization at room temperature for $30 \mathrm{~min}$, samples were electrophoresed for $1 \mathrm{~h}(3 \mathrm{~mA} / g e l$ tube). Lipoware computer software (Quantimetrix, Redondo Beach, CA, USA) was then used to divide LDL into small $(<255 \AA)$, medium (255-260 $)$, and large ( $>260 \AA$ ) particles, and to assess mean LDL particle size [10]. The intra-assay coefficients of variation (CV) for total cholesterol, HDL cholesterol, triacylglycerol, and LDL particle size were $3.6 \%, 4.8 \%, 2.5 \%$, and $4.1 \%$, respectively.

\section{Non-lipid coronary heart disease risk factors}

All measurements were taken at week 1 and 12 . Blood pressure was measured in triplicate with the subject in a seated position after a 10 -min rest. C-reactive protein (CRP) was measured in duplicate using Immulite 1000 High Sensitivity CRP kits (Diagnostic Products Corporation, Los Angeles, CA). Plasma homocysteine measurements were carried out in duplicate using HPLC with fluorometric detection. Adiponectin, leptin and resistin were measure by ELISA (R\&D Systems, Minneapolis, $\mathrm{MN})$. The intra-assay coefficients of variation (CV) for CRP, homocysteine, adiponectin, leptin, and resistin were $5.0 \%, 4.3 \%, 3.3 \%, 3.0 \%$, and $4.7 \%$, respectively.

\section{Statistics}

Results are presented as means \pm standard error of the mean (SEM). Tests for normality were included in the model. No variables were found to be not normal. Differences between groups at baseline were tested by independent samples $t$-test. Within-group changes from week 1 to 12 were tested by a paired $t$-test. Betweengroup differences were tested by an independent samples $t$-test. Sample size was calculated assuming a $10 \%$ change in LDL-cholesterol concentrations in the ADF group, with a power of $80 \%$ and an alpha risk of $5 \%$. P-values of $<0.05$ were considered significant. Data were analyzed by using SPSS software (version 21.0 for Mac OS X; SPSS Inc., Chicago, IL). 


\section{Results}

\section{Subject baseline characteristics and dropouts}

Thirty-two subjects commenced the study, with 30 completing the entire 12-week trial (Figure 1). After loss due to dropouts, the remaining subjects in each intervention group were as follows: $\operatorname{ADF}(n=15)$ and control $(n=15)$. Baseline characteristics of the subjects who completed the trial are presented in Table 1 . There were no significant differences at the beginning of the study between groups for age, sex, ethnicity, body weight, body composition, height or BMI.

\section{Energy intake, hunger, satisfaction and fullness}

Energy intake, hunger, satisfaction, and fullness are reported in Table 2. At baseline, there were no differences between the ADF and control groups for feed day energy intake. From week 1 to 12 of the study, energy intake remained constant on both feed and fast days in the ADF group. Adherence to the fast day protocol was high in the ADF group (98 $\pm 5 \%$ ). Hunger levels were moderate as baseline, and did not change by week 12 in either group. Satisfaction and fullness increased $(\mathrm{P}<0.01)$ from baseline to post-treatment in the ADF group, with no change in the control group.

\section{Weight loss and body composition}

Changes in body weight and body composition are displayed in Figure 2. Body weight decreased $(\mathrm{P}<0.001)$ by $5.2 \pm 0.9 \mathrm{~kg}(6.5 \pm 1.0 \%)$ in the ADF group, relative to the control group at week 12 . Fat mass was reduced $(\mathrm{P}<0.001)$ by $3.6 \pm 0.7 \mathrm{~kg}$, and fat free mass did not change, versus controls.

Table 1 Subject characteristics at baseline

\begin{tabular}{|c|c|c|c|}
\hline & ADF-ALL & Control & P-value $^{1}$ \\
\hline$n$ & 15 & 15 & \\
\hline Age (y) & $47 \pm 3$ & $48 \pm 2$ & 0.18 \\
\hline $\operatorname{Sex}(M / F)$ & $5 / 10$ & $3 / 12$ & 0.44 \\
\hline \multicolumn{4}{|l|}{ Ethnicity (n) } \\
\hline African American & 5 & 8 & 0.30 \\
\hline Caucasian & 8 & 6 & \\
\hline Hispanic & 2 & 1 & \\
\hline Other & 0 & 0 & \\
\hline Body weight (kg) & $77 \pm 3$ & $77 \pm 3$ & 0.79 \\
\hline Fat mass (kg) & $26 \pm 2$ & $27 \pm 1$ & 0.13 \\
\hline Fat free mass $(\mathrm{kg})$ & $51 \pm 3$ & $50 \pm 3$ & 0.78 \\
\hline Height (cm) & $171 \pm 3$ & $170 \pm 2$ & 0.71 \\
\hline BMI $\left(\mathrm{kg} / \mathrm{m}^{2}\right)$ & $26 \pm 1$ & $26 \pm 1$ & 0.75 \\
\hline
\end{tabular}

Values reported as mean \pm SEM. ADF: Alternate day fasting, BMI: Body mass index, $F$ : Female, $M$ : Male.

${ }^{1} \mathrm{P}$-value between groups at baseline: Independent samples $t$-test.

\section{Lipid coronary heart disease risk factors}

Changes in plasma lipids and LDL particle size are reported in Table 3. Total cholesterol concentrations decreased $(\mathrm{P}<0.01)$ in the ADF group when posttreatment values were compared to baseline. However, changes in total cholesterol levels were not significantly different from controls at week 12. LDL cholesterol concentrations were reduced $(\mathrm{P}=0.01)$ within the ADF group, but no significant between-group differences were noted. HDL cholesterol concentrations remained unchanged throughout the trial. Triacylglycerol concentrations decreased $(\mathrm{P}=0.01)$ in the ADF group relative to controls at week 12. Non-HDL cholesterol levels were reduced $(\mathrm{P}<0.01)$ within the ADF group, but no significant between-group differences were observed. LDL particle size increased $(\mathrm{P}<0.01)$ in the ADF group relative to controls by the end of the study.

\section{Non-lipid coronary heart disease risk factors}

Changes in blood pressure, homocysteine, CRP, and adipokines are shown in Table 4. Systolic and diastolic blood pressure decreased $(\mathrm{P}<0.05)$ within the ADF group, but no significant between-group differences were noted. CRP decreased $(\mathrm{P}=0.01)$ in the ADF group relative to controls at week 12 . Plasma adiponectin increased $(P<0.01)$ while leptin decreased $(P=0.03)$ in the ADF group versus controls by the end of the study. Plasma homocysteine and resistin concentrations remained unchanged after 12 weeks of treatment.

\section{Discussion}

This study shows, for the first time, that ADF is an effective strategy for moderate weight loss (6\%) in normal weight and overweight subjects. This diet strategy may also have cardio-protective effects in non-obese subjects, by way of lowering triacylglycerols, CRP and leptin, while increasing LDL particle size and adiponectin concentrations.

The primary goal of this study was to determine if non-obese individuals could benefit from ADF in terms of weight loss. Previous ADF studies implementing non-obese subjects report inconsistent findings $[5,6]$. While one study demonstrated decreases in body weight of $2 \%$ from baseline after 3 weeks of ADF [5], another study showed no effect after 2 weeks of diet [6]. The limited amount of weight loss reported previously is undoubtedly a factor of the short trial durations implemented $[5,6]$. Thus, we wanted to determine if the degree of weight loss could be amplified if the trial duration was extended to 12 weeks. We show here that normal weight and overweight subjects can indeed benefit from ADF, as body weight was reduced by $6 \%$ ( $5 \mathrm{~kg}$ ) by the end of the trial. This degree of weight loss in non-obese participants is similar to what has been 
Table 2 Energy intake, hunger, satisfaction and fullness during the 12-week study

\begin{tabular}{|c|c|c|c|c|c|c|c|}
\hline & Intervention & Week $1^{1}$ & Week 12 & P-value & P-value ${ }^{3}$ & Change $^{4}$ & P-value \\
\hline \multirow[t]{2}{*}{ Feed day energy intake $(\mathrm{kcal} / \mathrm{d})$} & ADF & $1874 \pm 136$ & $1856 \pm 229$ & 0.93 & 0.92 & $-18 \pm 186$ & 0.50 \\
\hline & Control & $1873 \pm 243$ & $1790 \pm 286$ & 0.71 & & $-82 \pm 75$ & \\
\hline Fast day energy intake (kcal/d) & ADF & $482 \pm 19$ & $489 \pm 20$ & 0.74 & & $7 \pm 5$ & \\
\hline \multirow[t]{2}{*}{ Hunger (mm) } & ADF & $5 \pm 1$ & $4 \pm 1$ & 0.44 & 0.56 & $-1 \pm 1$ & 0.38 \\
\hline & Control & $5 \pm 1$ & $5 \pm 1$ & 0.46 & & $0 \pm 1$ & \\
\hline \multirow[t]{2}{*}{ Satisfaction (mm) } & ADF & $4 \pm 1$ & $7 \pm 1$ & $<0.01$ & 0.81 & $3 \pm 1$ & 0.22 \\
\hline & Control & $6 \pm 1$ & $7 \pm 1$ & 0.34 & & $1 \pm 1$ & \\
\hline \multirow[t]{2}{*}{ Fullness (mm) } & ADF & $2 \pm 1$ & $4 \pm 1$ & $<0.01$ & 0.78 & $2 \pm 1$ & 0.01 \\
\hline & Control & $6 \pm 1$ & $6 \pm 1$ & 0.57 & & $0 \pm 1$ & \\
\hline
\end{tabular}

Values reported as mean \pm SEM. ADF: Alternate day fasting.

${ }^{1}$ Baseline values were not significantly different between intervention groups for any parameter: Independent samples $t$-test.

${ }^{2} \mathrm{P}$-value between week 1 and week 12: Paired $t$-test.

${ }^{3} \mathrm{P}$-value between groups at week 12: Independent samples $t$-test.

${ }^{4}$ Absolute change between week 1 and week 12 values.

${ }^{5} \mathrm{P}$-value between groups for absolute change: Independent samples $t$-test.

reported for obese individuals undergoing ADF [2-4]. For instance, Bhutani et al. [4] demonstrated 5\% (5 kg) weight loss after 12 weeks of ADF in obese men and women. In line with these findings, Klempel et al. [3] and Varady et al. [2] report 5-6\% (5-6 kg) weight loss after 8 weeks of treatment in obese subjects. Thus, ADF may produce a mean rate of weight loss of approximately $0.5 \mathrm{~kg} /$ week, independent of the starting weight or BMI class of the subject. Fat free mass was also retained after 12 weeks of ADF in non-obese individuals. This finding is similar to what has been reported in previous short-term studies of ADF [2-4]. As such, the beneficial preservation of fat free mass observed in obese individuals [2-4] may be replicated in non-obese subjects participating in ADF protocols.

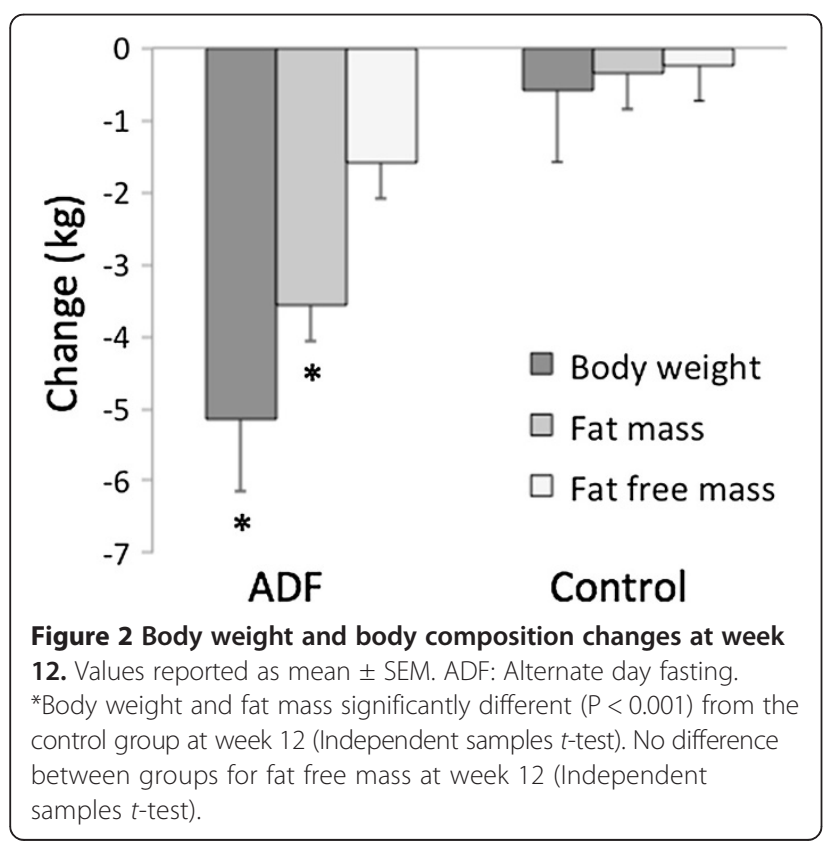

Our findings also indicate that normal weight and overweight subjects have no problem adhering to the fast day protocol for 12 weeks. Dietary adherence was very high at baseline (98\%), and did not wane over the course of the study. It should be noted, however, that one normal weight subject dropped out of the trial due to an inability to adhere to the diet. Notwithstanding, our dropout rate was still less than $10 \%$, which is similar to the dropout rate of studies performed in obese individuals [2-4]. Complementary to previous reports $[12,13]$, there was very little or no hyperphagic response on the feed day in response to the lack of food on the fast day. This lack of hyperphagia allowed for overall energy restriction to remain high throughout the study, and undoubtedly contributed to the sizeable degree of weight loss observed here. As for eating behaviors, perceived hunger was moderate at baseline and did not change by week 12 . This is contrary to findings in obese participants, which consistently show declines in hunger after 8-12 weeks of ADF [11,12]. Dietary satisfaction and feelings of fullness, on the other hand, increased from baseline to post-treatment. These increases in satisfaction and fullness have also been noted in obese subjects [11,12], and may play a role in long-term adherence to the diet.

The cardio-protective effects of ADF were also examined. Reductions in triacylglycerol concentrations (20\%) were noted after 12 weeks of ADF. LDL particle size also increased post-treatment (4 $\AA$ from baseline). These changes in lipid risk factors are in line with what has been reported for obese ADF subjects $[14,15]$. In two recent ADF studies, triacylglycerols decreased by $15 \%$ and LDL particle size increased by $2-3 \AA$ after 8 weeks of treatment in obese men and women $[14,15]$. Thus, ADF may improve plasma lipids to the same extent in non-obese subjects as it does in obese 
Table 3 Lipid coronary heart disease risk factor changes during the 12-week study

\begin{tabular}{|c|c|c|c|c|c|c|c|}
\hline & Intervention & Week $1^{1}$ & Week 12 & P-value ${ }^{2}$ & P-value ${ }^{3}$ & Change $^{4}$ & P-value ${ }^{5}$ \\
\hline \multirow[t]{2}{*}{ Total cholesterol (mg/dl) } & ADF & $201 \pm 9$ & $175 \pm 12$ & $<0.01$ & 0.12 & $-26 \pm 6$ & 0.50 \\
\hline & Control & $211 \pm 11$ & $202 \pm 9$ & 0.54 & & $-9 \pm 5$ & \\
\hline \multirow[t]{2}{*}{ LDL cholesterol (mg/dl) } & ADF & $118 \pm 9$ & $99 \pm 9$ & 0.01 & 0.82 & $-18 \pm 6$ & 0.29 \\
\hline & Control & $128 \pm 10$ & $119 \pm 6$ & 0.08 & & $-9 \pm 4$ & \\
\hline \multirow[t]{2}{*}{ HDL cholesterol (mg/dl) } & ADF & $56 \pm 3$ & $54 \pm 4$ & 0.49 & 0.77 & $-2 \pm 3$ & 0.51 \\
\hline & Control & $57 \pm 2$ & $58 \pm 4$ & 0.83 & & $1 \pm 2$ & \\
\hline \multirow[t]{2}{*}{ Triacylglycols (mg/dl) } & ADF & $109 \pm 13$ & $87 \pm 9$ & 0.06 & 0.01 & $-22 \pm 11$ & 0.22 \\
\hline & Control & $108 \pm 18$ & $118 \pm 19$ & 0.34 & & $10 \pm 7$ & \\
\hline \multirow[t]{2}{*}{ Non-HDL cholesterol (mg/dl) } & ADF & $149 \pm 11$ & $124 \pm 12$ & $<0.01$ & 0.54 & $-25 \pm 5$ & 0.96 \\
\hline & Control & $153 \pm 12$ & $144 \pm 10$ & 0.79 & & $-9 \pm 5$ & \\
\hline \multirow[t]{2}{*}{ LDL particle size $(\AA ̊)$} & ADF & $254 \pm 1$ & $258 \pm 2$ & $<0.01$ & $<0.01$ & $4 \pm 1$ & 0.13 \\
\hline & Control & $252 \pm 2$ & $250 \pm 3$ & 0.16 & & $-2 \pm 1$ & \\
\hline
\end{tabular}

Values reported as mean \pm SEM. ADF: Alternate day fasting.

${ }^{1}$ Baseline values were not significantly different between intervention groups for any parameter: Independent samples $t$-test.

${ }^{2} \mathrm{P}$-value between week 1 and week 12: Paired $t$-test.

${ }^{3} \mathrm{P}$-value between groups at week 12 : Independent samples $t$-test.

${ }^{4}$ Absolute change between week 1 and week 12 values.

${ }^{5} \mathrm{P}$-value between groups for absolute change: Independent samples $t$-test.

subjects. Additional vascular benefits, including decreases in circulating leptin and CRP concentrations, in conjunction with increases in adiponectin, were also noted in non-obese subjects undergoing ADF. As for HDL cholesterol, homocysteine, and resistin concentrations, no effect was observed. This lack of effect is not surprising as these CHD risk parameters are generally only improved with $>10 \%$ weight loss [16-18].
It will be of interest in future studies to determine how alterations in macronutrient intake on the fast day may affect weight loss and cardiovascular outcomes. For instance, it has been well established that Mediterranean [19] and certain low-carbohydrate diets [20] help to maintain a healthy body weight and reduce CHD risk. Whether further reductions in body weight and CHD risk would occur if ADF were combined with

Table 4 Non-lipid coronary heart disease risk factor changes during the 12-week study

\begin{tabular}{|c|c|c|c|c|c|c|c|}
\hline & Intervention & Week $1^{1}$ & Week 12 & P-value ${ }^{2}$ & P-value ${ }^{3}$ & Change $^{4}$ & P-value \\
\hline \multirow[t]{2}{*}{ Systolic BP (mm Hg) } & $\mathrm{ADF}$ & $124 \pm 4$ & $117 \pm 4$ & 0.02 & 0.85 & $-7 \pm 2$ & 0.51 \\
\hline & Control & $119 \pm 3$ & $120 \pm 4$ & 0.67 & & $1 \pm 3$ & \\
\hline \multirow[t]{2}{*}{ Diastolic BP (mm Hg) } & ADF & $78 \pm 3$ & $72 \pm 2$ & 0.03 & 0.05 & $-6 \pm 2$ & 0.17 \\
\hline & Control & $82 \pm 4$ & $84 \pm 5$ & 0.28 & & $2 \pm 6$ & \\
\hline \multirow[t]{2}{*}{ Homocysteine (umol/dl) } & $\mathrm{ADF}$ & $9 \pm 1$ & $9 \pm 1$ & 0.37 & 0.50 & $0 \pm 1$ & 0.21 \\
\hline & Control & $9 \pm 1$ & $9 \pm 1$ & 0.86 & & $0 \pm 1$ & \\
\hline \multirow[t]{2}{*}{ C-reactive protein $(\mathrm{mg} / \mathrm{L})$} & ADF & $2 \pm 1$ & $1 \pm 1$ & 0.29 & 0.01 & $-1 \pm 1$ & 0.01 \\
\hline & Control & $1 \pm 1$ & $1 \pm 1$ & 0.78 & & $0 \pm 1$ & \\
\hline \multirow[t]{2}{*}{ Adiponectin (ng/ml) } & $\mathrm{ADF}$ & $10728 \pm 1251$ & $11401 \pm 1197$ & 0.58 & 0.15 & $672 \pm 1191$ & $<0.01$ \\
\hline & Control & $11350 \pm 1369$ & $10509 \pm 1316$ & 0.26 & & $-842 \pm 623$ & \\
\hline \multirow[t]{2}{*}{ Leptin (ng/ml) } & $\mathrm{ADF}$ & $25 \pm 4$ & $15 \pm 3$ & 0.04 & 0.55 & $-10 \pm 3$ & 0.03 \\
\hline & Control & $22 \pm 7$ & $18 \pm 6$ & 0.07 & & $-4 \pm 3$ & \\
\hline \multirow[t]{2}{*}{ Resistin (ng/ml) } & $\mathrm{ADF}$ & $18 \pm 3$ & $15 \pm 4$ & 0.15 & 0.57 & $-3 \pm 3$ & 0.20 \\
\hline & Control & $23 \pm 4$ & $21 \pm 4$ & 0.26 & & $-2 \pm 2$ & \\
\hline
\end{tabular}

Values reported as mean \pm SEM. ADF: Alternate day fasting.

${ }^{1}$ Baseline values were not significantly different between intervention groups for any parameter: Independent samples $t$-test.

${ }^{2} \mathrm{P}$-value between week 1 and week 12: Paired $t$-test.

${ }^{3} \mathrm{P}$-value between groups at week 12 : Independent samples $t$-test.

${ }^{4}$ Absolute change between week 1 and week 12 values.

${ }^{5} \mathrm{P}$-value between groups for absolute change: Independent samples $t$-test. 
Mediterranean or low-carbohydrate diets, undoubtedly warrants investigation.

A couple of adverse events were reported during the study. Two subjects experienced mild headaches during week 1 of the trial, which may or may not be related to dietary treatment. One other subject reported constipation during week 1 and 2 of the trial. The subject was advised to consume more fruits and vegetables on feed days, and the constipation subsided by week 3 of the dietary intervention period.

This study has several limitations. First and foremost, it must be acknowledged that this pilot study was originally designed to compare the effects of ADF in normal weight versus overweight individuals on body weight and CHD risk. Due to a low recruitment rate, we were only able to recruit $\mathrm{n}=8$ subjects into the normal weight group and $n=8$ subjects into the overweight group. In view of this, we decided to combine the normal weight and overweight groups into one group to increase sample size. This post hoc change should be taken into consideration when interpreting the findings of this paper. Secondly, physical activity was not assessed throughout the trial, thus the degree of weight loss associated with increased energy expenditure from exercise is not known. Thirdly, the sample size of each group was small $(n=15)$. Thus, this study may not be adequately powered to detect changes in certain CHD risk parameters (e.g. resistin). Fourthly, this study employed food records to assess dietary intake/adherence. It is well known that overweight subject underreport food intake by $\sim 30 \%[21,22]$. Thus, our findings for the hyperphagic response on the feed day may be inaccurate.

In summary, these preliminary findings suggest that $\mathrm{ADF}$ is a viable weight loss strategy for normal weight and overweight individuals wishing to lose a moderate amount of weight $(5-6 \mathrm{~kg}$ ) within a relatively short period of time (12 weeks). This diet may also help lower CHD risk in non-obese individuals, though further investigation is warranted to confirm these effects. It should also be noted that the purpose of this paper is to report pilot feasibility findings. It is our hope that this preliminary data will be utilized to design larger-scale longer-term trials with similar objectives, in normal weight and overweight participants undergoing ADF.

\section{Competing interest}

The authors have no conflicts of interest to report.

\section{Authors' contributions}

KAV designed the experiment, analyzed the data, and wrote the manuscript. SB, MCK, CMK, and JFT assisted with the conduction of the clinical trial and performed the laboratory analyses. JMH assisted with the data analyses and the preparation of the manuscript. KKH and YC assisted with the laboratory analyses. All authors read and approved the final manuscript.

\section{Funding source}

Departmental grant from Kinesiology and Nutrition at the University of Illinois, Chicago.

Received: 3 July 2013 Accepted: 4 November 2013

Published: 12 November 2013

\section{References}

1. Varady KA, Hellerstein MK: Alternate-day fasting and chronic disease prevention: a review of human and animal trials. Am J Clin Nutr 2007, 86:7-13.

2. Varady KA, Bhutani S, Church EC, Klempel MC: Short-term modified alternate-day fasting: a novel dietary strategy for weight loss and cardioprotection in obese adults. Am J Clin Nutr 2009, 90:1138-1143.

3. Klempel MC, Kroeger CM, Varady KA: Alternate day fasting (ADF) with a high-fat diet produces similar weight loss and cardio-protection as ADF with a low-fat diet. Metabolism 2013, 62:137-143.

4. Bhutani S, Klempel MC, Kroeger CM, Trepanowski JF, Varady KA: Alternate day fasting and endurance exercise combine to reduce body weight and favorably alter plasma lipids in obese humans. Obesity (Silver Spring) 2013. Epub ahead of print.

5. Heilbronn LK, Smith SR, Martin CK, Anton SD, Ravussin E: Alternate-day fasting in nonobese subjects: effects on body weight, body composition, and energy metabolism. Am J Clin Nutr 2005, 81:69-73.

6. Halberg N, Henriksen M, Söderhamn N, Stallknecht B, Ploug T, Schjerling P, Dela F: Effect of intermittent fasting and refeeding on insulin action in healthy men. J Appl Physiol 2005, 99:2128-2136.

7. Mifflin MD, St Jeor ST, Hill LA, Scott BJ, Daugherty SA, Koh YO: A new predictive equation for resting energy expenditure in healthy individuals. Am J Clin Nutr 1990, 51:241-247.

8. Gidding SS, Lichtenstein AH, Faith MS, Karpyn A, Mennella JA, Popkin B, Rowe J, Van Horn L, Whitsel L: Implementing American heart association pediatric and adult nutrition guidelines: a scientific statement from the American heart association nutrition committee of the council on nutrition, physical activity and metabolism, council on cardiovascular disease in the young, council on arteriosclerosis, thrombosis and vascular biology, council on cardiovascular nursing, council on epidemiology and prevention, and council for high blood pressure research. Circulation 2009, 119:1161-1175.

9. Flint A, Raben A, Blundell JE, Astrup A: Reproducibility, power and validity of visual analogue scales in assessment of appetite sensations in single test meal studies. Int J Obes Relat Metab Disord 2000, 24:38-48.

10. Chung M, Lichtenstein AH, Ip S, Lau J, Balk EM: Comparability of methods for LDL subfraction determination: a systematic review. Atherosclerosis 2009, 205:342-348.

11. Varady KA, Lamarche B: Lipoprint adequately estimates LDL size distribution, but not absolute size, versus polyacrylamide gradient gel electrophoresis. Lipids 2011, 46:1163-1167.

12. Klempel MC, Bhutani S, Fitzgibbon M, Freels S, Varady KA: Dietary and physical activity adaptations to alternate day modified fasting: implications for optimal weight loss. Nutr J 2010, 9:35.

13. Bhutani S, Klempel MC, Kroeger CM, Aggour E, Calvo Y, Trepanowski JF, Hoddy KK, Varady KA: Effect of exercising while fasting on eating behaviors and food intake. J Int Soc Sports Nutr 2013, 10(1):50.

14. Varady KA, Bhutani S, Klempel MC, Lamarche B: Improvements in LDL particle size and distribution by short-term alternate day modified fasting in obese adults. Br J Nutr 2011, 105:580-583.

15. Klempel MC, Kroeger CM, Varady KA: Alternate day fasting increases LDL particle size independently of dietary fat content in obese humans. Eur J Clin Nutr 2013. Epub ahead of print.

16. Dattilo AM, Kris-Etherton PM: Effects of weight reduction on blood lipids and lipoproteins: a meta-analysis. Am J Clin Nutr 1992, 56:320-328.

17. Ryan AS, Nicklas BJ: Reductions in plasma cytokine levels with weight loss improve insulin sensitivity in overweight and obese postmenopausal women. Diabetes Care 2004, 27:1699-1705.

18. Jae SY, Fernhall B, Heffernan KS, et al: Effects of lifestyle modifications on C-reactive protein: contribution of weight loss and improved aerobic capacity. Metabolism 2006, 55:825-831.

19. Kris-Etherton P, Eckel RH, Howard BV, St Jeor S, Bazzarre TL: Nutrition committee population science committee and clinical science committee of the American heart association. AHA science advisory: 
Lyon diet heart study. Benefits of a Mediterranean-style, National Cholesterol Education Program/American Heart Association Step I dietary pattern on cardiovascular disease. Circulation 2001, 103:1823-1825.

20. Schwingshackl L, Hoffmann G: Low-carbohydrate diets and cardiovascular risk factors. Obes Rev 2013, 14:183-184.

21. Scagliusi FB, Ferriolli E, Pfrimer K, Laureano C, Cunha CS, Gualano B,

Lourenço BH, Lancha AH Jr: Characteristics of women who frequently under report their energy intake: a doubly labelled water study.

Eur J Clin Nutr 2009, 63:1192-1199.

22. Nielsen BM, Nielsen MM, Toubro S, Pedersen O, Astrup A, Sørensen TI, Jess T, Heitmann BL: Past and current body size affect validity of reported energy intake among middle-aged Danish men. J Nutr 2009, 139:2337-2343.

doi:10.1186/1475-2891-12-146

Cite this article as: Varady et al:: Alternate day fasting for weight loss in normal weight and overweight subjects: a randomized controlled trial. Nutrition Journal 2013 12:146.

\section{Submit your next manuscript to BioMed Central and take full advantage of:}

- Convenient online submission

- Thorough peer review

- No space constraints or color figure charges

- Immediate publication on acceptance

- Inclusion in PubMed, CAS, Scopus and Google Scholar

- Research which is freely available for redistribution 